\title{
Erratum to: Ultraviolet light-emitting diode (UV LED) trap for the West Indian sweet potato weevil, Euscepes postfasciatus (Coleoptera: Curculionidae)
}

\author{
Masako Katsuki $\cdot$ Yusuke Omae $\cdot$ Kensuke Okada $\cdot$ \\ Toru Kamura $\cdot$ Takashi Matsuyama • \\ Dai Haraguchi $\cdot$ Tsuguo Kohama $\cdot$ Takahisa Miyatake
}

Published online: 11 September 2012

(C) The Japanese Society of Applied Entomology and Zoology 2012

Erratum to: Appl Entomol Zool (2012) 47:285-290

DOI 10.1007/s13355-012-0113-y

The original article was published with the incorrect title. The correct title should read: "Ultraviolet light-emitting diode (UV LED) trap for the West Indian sweet potato weevil, Euscepes postfasciatus (Coleoptera: Curculionidae)”.

The online version of the original article can be found under doi:10.1007/s13355-012-0113-y.

M. Katsuki

Graduate School of Environmental Science, Okayama

University, 1-1-1 Tsushima-naka, Okayama 700-8530, Japan

Y. Omae - T. Kamura

Faculty of Agriculture, Okayama University,

1-1-1 Tsushima-naka, Okayama 700-8530, Japan

K. Okada $\cdot$ T. Miyatake $(\bowtie)$

Graduate School of Environmental and Life Science, Okayama

University, 1-1-1 Tsushima-naka, Okayama 700-8530, Japan

e-mail: miyatake@cc.okayama-u.ac.jp

T. Matsuyama

Okinawa Prefectural Plant Protection Center, Maji, Naha,

Okinawa 902-0072, Japan

D. Haraguchi · T. Kohama

Okinawa Prefectural Agricultural Research Center,

820 Makabe, Itoman, Okinawa 901-0336, Japan 